\title{
EDUCAÇÃO E COVID-19: AS TECNOLOGIAS DIGITAIS MEDIANDO A APRENDIZAGEM EM TEMPOS DE PANDEMIA
}

\author{
EDUCATION AND COVID-19: DIGITAL TECHNOLOGIES MEDIATING \\ THE LEARNING PROCESS IN TIMES OF A PANDEMIC
}

\section{EDUCACIÓN Y COVID-19: LAS TECNOLOGÍAS DIGITALES MEDIANDO EL APRENDIZAJE EN TIEMPOS DE PANDEMIA}

\author{
Verissimo Barros dos Santos Junior ${ }^{i}$ \\ Jean Carlos da Silva Monteiro ii $(\mathbb{C}$
}

\begin{abstract}
Resumo: O artigo aborda as tecnologias digitais como recurso para mediação do processo de aprendizagem em tempos de pandemia. O objetivo é apresentar o Google Classroom (ferramenta assíncrona) e o aplicativo ZOOM (ferramenta síncrona) e suas potencialidades pedagógicas para o ensino remoto. A metodologia do estudo, de caráter descritiva e exploratória, aborda um estudo bibliográfico e documental em que se discute as contribuições das tecnologias digitais para o processo de aprendizagem no momento em que se enfrenta a pandemia do novo coronavírus (COVID - 19). Constata que, em um momento de adaptação do processo de aprendizagem, o Google Classroom e o aplicativo ZOOM se apresentam como recursos eficazes para mediação remota, mas que sua integração estratégica no processo formativo demanda formação tecnológica dos professores.
\end{abstract}

\begin{abstract}
The article addresses digital technologies as a key element for mediating the learning process in pandemic times. It aims to present the pedagogical potential for remote teaching with Google Classroom and ZOOM application, asynchronous and synchronous communication tools, respectively. This study of a descriptive- exploratory nature, uses bibliographic and documentary analysis to discuss the contributions of digital technologies to the learning process in times when education is forced to face a new scenario due to the COVID - 19. The results demonstrate how the learning process had to adapt in times of pandemic, especially with the use of digital technologies. In this context, the study considers that although Google Classroom and the ZOOM applications are effective tools to remote mediation, their strategic insertion into the formative process demands more technology training for teachers.
\end{abstract}

Resumen: El articulo aborda las tecnologías digitales como recursos para la mediación del proceso de aprendizaje en tiempos de pandemia. El objetivo es presentar Google ClassRoom (herramienta asíncrona) y la aplicación ZOOM (herramienta síncrona) y sus potencialidades pedagógicas para la enseñanza a distancia. La metodología de estudio, de carácter descriptivo y exploratorio, aborda un estudio bibliográfico y documental en que se discuten las contribuciones de las tecnologías digitales para el proceso de aprendizaje en el momento en que se enfrenta la pandemia del coronavirus (COVID - 19). Constata que, en el momento de adaptación del proceso de aprendizaje, el Clases Room y la aplicación ZOOM se presentan como recursos eficaces para la mediación a distancia, pero que su integración estratégica en el proceso formativo demanda formación tecnológica de los profesores.

Palavras-chave: Tecnologias digitais; Aprendizagem; Covid-19.

Keywords: Digital technologies; Learning; Covid-19.

Palabras claves: Tecnologías digitales; Aprendizaje; Covid-19. 


\section{INTRODUÇÃO}

Diante da pandemia do novo coronavírus (COVID - 19), o Ministério da Educação (MEC) atendeu à solicitação feita pela Associação Brasileira de Mantenedoras de Ensino Superior (ABMES), bem como as orientações do Conselho Nacional de Educação (CNE), e publicou a portaria $n^{\circ} 343$, de 17 de março de 2020, que regulamenta as Instituições de Ensino a substituírem aulas presenciais pelo ensino a distância (EaD) pelo prazo de 30 dias ou, em caráter excepcional, podendo ser prorrogada enquanto durar a pandemia (BRASIL, 2020).

As Instituições de Ensino e professores acataram as recomendações do MEC, fecharam suas dependências temporariamente e passaram a vislumbrar um leque de novas oportunidades de utilização estratégias das atuais Tecnologias de Informação e Comunicação (TIC), a fim de promover um processo formativo eficiente, capaz de levar conhecimento e oportunidade de aprendizagem para bilhões de alunos por meio dos recursos midiáticos oferecidos pela internet.

Diante desse contexto, este artigo aborda as tecnologias digitais como recurso para mediação do processo de aprendizagem em tempos de pandemia. O objetivo é apresentar o Google Classroom (ferramenta assíncrona) e o aplicativo ZOOM (ferramenta síncrona) e suas potencialidades pedagógicas para o ensino remoto.

A metodologia do estudo, de caráter descritiva e exploratória, aborda um estudo bibliográfico e documental em que se discute as contribuições das tecnologias digitais para o processo de aprendizagem no momento em que se enfrenta a pandemia do novo coronavírus (COVID - 19).

\section{Novo Coronavírus (Covid - 19)}

Segundo o Ministério da Saúde (2020), o novo coronavírus é um vírus que causa infecções respiratórias, provoca a doença chamada COVID - 19. O novo agente do coronavírus foi descoberto em 31 de dezembro de 2019 após casos registrado na cidade de Wuban, na China.

A principal forma de contágio do COVID - 19 é o contato com uma pessoa infectada, que transmite o vírus por meio de tosse e espirros. Também se propaga quando a pessoa entra em contato com um objeto contaminado e depois toca nos olhos, nariz ou boca.

Para a Organização Mundial da Saúde (2020), pode-se estar com o COVID - 19 por até 14 dias antes de apresentar os sintomas, que são febre, cansaço e tosse seca. A maioria 
das pessoas (cerca de 80\%) se recupera da doença sem a necessidade de tratamentos especiais.

De acordo com o Ministério da Saúde (2020), em casos mais raros, ela pode atingir um quadro clínico mais grave e até fatal. Idosos e pessoas com outras condições médicas (como asma, diabetes e doença cardíaca) são vulneráveis a desenvolver problemas mais sérios.

A Organização Mundial da Saúde (2020) declarou em 30 de janeiro de 2020 que a pandemia do COVID - 19 se constitui em uma Emergência de Saúde Pública de Importância Internacional (ESPII), o mais alto nível de alerta emergencial da Organização, conforme previsto no Regulamento Sanitário Internacional.

Diante disso, buscou-se a cooperação e a solidariedade global para interromper a propagação do vírus a partir do isolamento social. De acordo com o Ministério da Saúde (2020), o isolamento é definido como a ação que objetiva a separação de pessoas sintomáticas ou assintomáticas, em investigação clínica e laboratorial, de maneira a evitar a propagação do vírus e transmissão local.

Com o avanço do número de casos de pessoas infectadas pelo COVID - 19, escolas públicas e privadas, da educação básica à superior, dos 26 estados brasileiros e do Distrito Federal, cumpriram as determinações do governo federal para a suspensão das aulas, conforme a Portaria no $343 / 2020$.

\section{PORTARIA No $343 / 2020$}

A portaria no 343 publicada no Diário Oficial da União, em 17 de março de 2020, dispõe sobre a substituição das aulas presenciais por aulas em meios digitais enquanto durar a situação de pandemia do COVID - 19 (BRASIL, 2020). A medida é válida por 30 dias ou enquanto durar a situação da pandemia. Por meio da portaria, o MEC resolve:

Art. $1^{\circ}$ Autorizar, em caráter excepcional, a substituição das disciplinas presenciais, em andamento, por aulas que utilizem meios e tecnologias de informação e comunicação, nos limites estabelecidos pela legislação em vigor, por instituição de educação superior integrante do sistema federal de ensino, de que trata o art. $2^{\circ}$ do Decreto $n^{\circ} 9.235$, de 15 de dezembro de 2017 (BRASIL, 2020, p.01).

A Portaria informa ainda que as Instituições de Ensino, integrantes do sistema federal de ensino, devem comunicar ao MEC, por meio de Ofício, a opção que será adotada como medida de prevenção ao COVID-19. 
Substituição das disciplinas presenciais, em andamento, por aulas que utilizem meios e tecnologias de informação e comunicação, nos limites estabelecidos pela legislação em vigor, de que trata o art. $2^{\circ}$ do Decreto $\mathrm{n}^{\circ}$ 9.235, de 15 de dezembro de 2017; Suspensão das atividades acadêmicas presenciais, desde que cumpram os dias letivos e horas/aula estabelecidos na legislação em vigor; Alteração do calendário de férias, desde que cumpram os dias letivos e horas-aula estabelecidos na legislação em vigor (BRASIL, 2020, p.01).

A Organização das Nações Unidas para a Educação, a Ciência e a Cultura (UNESCO) realizou a primeira contagem global da situação educacional impactada pelo COVID - 19. Foram registrados quase 300 milhões de alunos, em 22 países, de três continentes, afetados pelo fechamento de escolas devido à expansão do vírus (UNESCO, 2020)

Diante do ocorrido, as instituições de ensino estão buscando alternativas para a mediar o processo formativo de forma remota para dar continuidade às aulas. As tecnologias digitais se apresentam como recursos favoráveis para a mediação, sobretudo no que tange as diferentes possibilidades de transformar tais ferramentas em salas de aulas virtuais, que possibilitam a interação de alunos e professores.

\section{TECNOLOGIAS DigitAIS NA EDUCAÇÃo}

Em uma sociedade em que mais de 5 bilhões de pessoas usam aparelho celular (GSMA, 2019), o acesso às informações se torna cada vez mais rápido. O surgimento de tecnologias emergentes, assim como a possibilidade de armazenamento em nuvem ${ }^{1}$, evoluem a cada instante, modificando a todo momento o conceito de novo e de inovação.

A sociedade passa por um amplo processo de transformação, sobretudo na evolução digital. Hoje em dia, por exemplo, muitas tarefas - que aconteciam de forma presencial - não se realizam mais sem a presença dos dispositivos digitais, de modo online. Vive-se, então, em um contexto social em que a conectividade e a colaboração fazem parte da vida de milhões de pessoas desde cedo.

Conforme Conforto e Vieira (2015, p. 45):

A abundância de recursos e de conte dos físicos e digitais, aliada ampliação dos serviços de conexão móvel com a Internet, de armazenamento em nuvem e a evolução da telefonia celular, promoveram o surgimento de uma nova modalidade de educação, a Aprendizagem Móvel.

\footnotetext{
${ }^{1} \mathrm{O}$ armazenamento em nuvem é uma tecnologia que possibilita guardar dados na internet por meio de um servidor online sempre disponível. É possível armazenar, editar, compartilhar e excluir arquivos, documentos, fotos, vídeos, contatos e aplicativos livremente. Este tipo de armazenamento dispensa a necessidade de um armazenamento local, seja em um computador desktop, notebook, smartphone ou tablet.
} 
Isso representa que, a tecnologia - antes vista como algo que tirava o sujeito do convívio social - tornou-se cada vez mais utilizada e pensada para benefício coletivo. Para Conforto e Vieira (2015), o celular não pode ser considerado apenas como fonte de entretenimento, mas como uma ferramenta que, quando planejada pedagogicamente, também pode auxiliar o processo educacional.

Diante dessa evolução, a educação e suas relações de ensino-aprendizado vêm, a passos lentos, acompanhando as transformações sociais advindas dos impactos das tecnologias digitais. Alunos hiperconectados ${ }^{2}$ em sala de aula têm acesso agora à diferentes fontes de informação, sendo atualizados a cada momento sobre os acontecimentos que ocorrem no mundo. Neste sentido, é essencial repensar sobre a utilização das TIC em sala de aula como instrumento para mediação da aprendizagem.

Com as suspensões das aulas, muito se fala do uso das tecnologias digitais para mediar o processo de aprendizagem remota ${ }^{3}$ como alternativa para não suspender as aulas. Tendo que recorrer ao EaD, algumas instituições estão se adaptando para utilizar as plataformas digitais para fins de mediação da aprendizagem.

No entanto, nem todos os estudantes do país têm acesso a esses recursos. Segundo o Fundo das Nações Unidas para a Infância (UNICEF), 154 milhões de estudantes estão sem aulas na América Latina e Caribe. A entidade alerta que a situação poderá se estender, considerando ainda que, diante do cenário de pandemia, há risco de abandono escolar definitivo (UNICEF, 2020).

A fim de sugerir ferramentas para a mediação remota em tempos de COVID - 19, apresenta-se, nas próximas seções, o Google Classroom e o app ZOOM, recursos educacionais online e gratuitos, que podem promover um processo formativo diferenciado.

\section{Google Classroom}

O Google Classroom ${ }^{4}$, exibido na Figura 1, plataforma muito utilizada para o ensino a distância e/ou mediação com metodologias ativas ${ }^{5}$, por meio do ensino híbrido ${ }^{6}$, sofreu um

\footnotetext{
2 Alunos que utilizam múltiplos meios de comunicação como e-mail, mensagens instantâneas, telefone, contato presencial e serviços de informação intrinsecamente ligado ao uso excessivo dos meios de conectividade e de informação.

$3 \mathrm{O}$ ensino remoto praticado na pandemia assemelha-se ao $\mathrm{EaD}$ apenas no que se refere a uma educação mediada pela tecnologia. Mas os princípios seguem sendo os mesmos da educação presencial. A EaD pressupõe o apoio de tutores de forma atemporal, carga horária diluída em diferentes recursos midiáticos e atividades síncronas e assíncronas. O ensino remoto proporciona o contato virtual diário com o professor da disciplina.

${ }^{4}$ Site da ferramenta: https://classroom.google.com
} 
grande aumento em seu download e utilização após ser divulgado o decreto do MEC anunciando a paralisação das aulas presenciais.

\section{Figura 1 - Página inicial do Google Classroom}

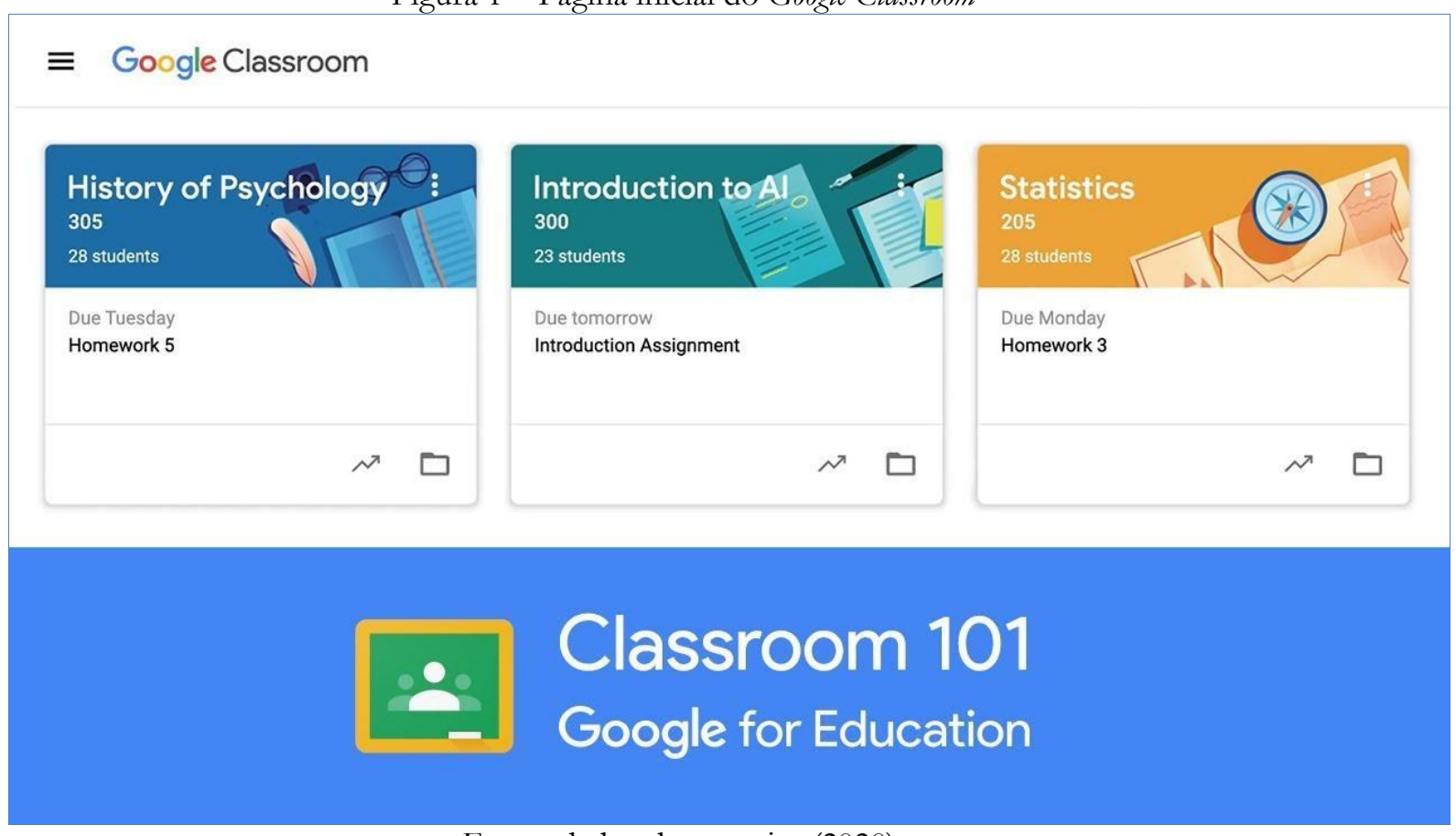

Fonte: dados da pesquisa (2020).

A plataforma mais escolhida para mediação remota, pois não necessita de instalação local e um servidor exclusivo. A ferramenta é online, abriga alunos e professores, facilitando a entrada (login) e a integração de diferentes recursos disponibilizados pelo próprio Google como: Gmail, Google Drive, Hangouts', Google Docs ${ }^{10}$ e Google Forms ${ }^{11}$ (GOOGLE CLASSROOM, 2020).

Além do uso em computadores, a plataforma dispõe da possibilidade de ser utilizada em smartphones e tablets, por meio de um aplicativo próprio, disponível na Google

\footnotetext{
${ }^{5}$ Metodologia ativa de aprendizagem é um processo amplo e possui como característica a inserção do aluno como agente principal responsável pela sua aprendizagem, comprometendo-se com seu aprendizado.

${ }^{6}$ Ensino híbrido é a metodologia que combina aprendizado online com o offline, em modelos que mesclam momentos em que o aluno estuda sozinho, de maneira virtual, e paralelamente em polos de estudo, em que a aprendizagem ocorre de forma presencial, valorizando a interação entre aluno e professor.

${ }^{7}$ Gmail é um serviço gratuito de correio eletrônico criado pela Google com mais de 425 milhões de usuários em todo o mundo.

${ }^{8}$ Google Drive é um serviço de armazenamento e sincronização de arquivos. Abriga o Google Docs, um leque de aplicações de produtividade, que oferece a edição de documentos, folhas de cálculo e apresentações.

9 Google Hangouts é uma plataforma de comunicação, desenvolvida pela Google, que inclui mensagens instantâneas, chat de vídeo e SMS.

${ }^{10} \mathrm{O}$ Google Docs é um serviço para Web, Android e iOS onde é possível criar, editar e visualizar documentos de texto e compartilhá-los com amigos e contatos profissionais. Com a possibilidade de trabalhar offline, esta ferramenta pode salvar os arquivos tanto no drive online do Google quanto na memória do dispositivo.

11 O Google Forms é um serviço que tem por objetivo facilitar a criação de formulários e questionários diversos. Disponível gratuitamente para todos que possuírem uma conta Google, o serviço pode ser acessado em diversas plataformas, como web, desktop e celular. Ele é útil para todos aqueles que queiram fazer um formulário de pesquisa ou de coleta de opiniões.
} 
Play $^{12}$ e Apple Store ${ }^{13}$. Seu diferencial é o sistema de feedback que é oferecido para que o professor dê todo suporte aos alunos nas atividades, desde o início até o final do processo formativo.

O sistema de atividade ou postagem na plataforma gera automaticamente uma notificação direta no e-mail do aluno, deixando-o sempre atualizado sobre os conteúdos inseridos no ambiente virtual, fator que possibilita maior a interação e engajamento entre a turma (GOOGLE CLASSROOM, 2020).

Ao fazer login, o professor tem opções de ferramentas para postagem no ambiente virtual:

a) Mural: neste campo, professores e alunos têm acesso às atualizações da plataforma, datas das postagens e últimas informações, assim também como avisos e comentários.

b) Atividades: nessa área, o professor realiza as postagens. As atividades podem ser disponibilizadas de diferentes formas, a exemplo das opções dispostas na Tabela 1:

Tabela 1 - Tipos de atividades realizadas no Google Classroom

\begin{tabular}{|c|c|}
\hline Atividade & $\begin{array}{l}\text { Tarefas com enunciados curtos e respostas } \\
\text { curtas. Nesse tipo de atividade, a ferramenta } \\
\text { sugere que se dê preferência pela realização de } \\
\text { perguntas objetivas. }\end{array}$ \\
\hline Atividade com teste & $\begin{array}{l}\text { As tarefas deste recurso são feitas com o } \\
\text { auxílio do bank quiz, (google formulários). Ao } \\
\text { selecionar essa opção de atividade, a } \\
\text { plataforma abre automaticamente uma criação } \\
\text { do forms, assim o professor pode produzir } \\
\text { questionários e, a partir da aplicação deles, } \\
\text { identificar os erros, acertos, além do feedback da } \\
\text { pontuação dos alunos na tarefa. }\end{array}$ \\
\hline Pergunta & $\begin{array}{l}\text { Neste item, o professor pode realizar o fórum. } \\
\text { Atividade em que um questionamento é } \\
\text { lançado para os alunos possam discutir e } \\
\text { apresentar suas opiniões sobre uma temática } \\
\text { abordada. }\end{array}$ \\
\hline Material & $\begin{array}{l}\text { Permite a postagem de diferentes arquivos } \\
\text { multimídia para que sejam compartilhados em } \\
\text { nuvem, via Google Drive, por meio de links, ou } \\
\text { até mesmo em redes e mídias sociais como o } \\
\text { YouTube. }\end{array}$ \\
\hline Reutilizar postagem & $\begin{array}{l}\text { Viabiliza que postagens já utilizadas em outras } \\
\text { turmas possam ser copiadas para outras. }\end{array}$ \\
\hline
\end{tabular}

Fonte: dados da pesquisa (2020).

12 Google Play é um serviço operacional Android de distribuição digital de aplicativos, jogos, filmes, programas de televisão, músicas e livros, desenvolvido e operado pela Google.

13 A App Store é um serviço de distribuição digital de aplicativos. Ela é a loja oficial de aplicativos para o sistema operacional $i O S$, da Apple. A loja permite que os usuários naveguem e baixem aplicativos desenvolvidos com o kit de desenvolvimento de software para iOS. 
Todas as formas de criar atividades, a exemplo das supracitadas acima, podem ser postadas, salvas, programadas ou arquivadas. A programação da postagem facilita o planejamento do professor, principalmente quando dispõem de várias turmas (GOOGLE CLASSROOM, 2020).

Todas as atividades serão analisadas pelo professor e cada uma delas vai receber uma pontuação específica. A Figura acima apresenta que o recurso dispõe de pontuação de 0 a 100 pontos, que podem ser modificadas de acordo com o planejamento do professor ou até mesmo decidir não pontuar determinada atividade.

c) Pessoas: nesta guia é organizada uma listagem com os nomes dos alunos e professores cadastrados na turma. Esta guia permite também o envio automático de e-mail convite para que novos alunos participem da turma.

d) Notas: funcionam como um diário de classe, em que são divulgadas as postagens feitas pelos professores e pelos alunos.

O Google Classroom vem sendo aprimorado constantemente pelos seus criadores por meio de feedbacks fornecidos pelos usuários da plataforma. Daudt (2015) cita algumas contribuições do Google Classroom que são: criação de turmas virtuais; lançamento de comunicados; criação de avaliações; receber os trabalhos dos alunos; organização de todo material de maneira facilitada e otimização da comunicação entre professor e aluno.

Compreende-se o Google Classroom como proposta de ferramentas assíncronas ${ }^{14} \mathrm{da}$ educação remota, que são aquelas consideradas desconectadas do momento real e/ou atual: não é necessário que os alunos e professores estejam conectados ao mesmo tempo para que as tarefas sejam concluídas (GOOGLE CLASSROOM, 2020).

Dessa forma, o aluno tem todo o conteúdo a qualquer momento na plataforma, permitindo-o a liberdade para acessar o material virtualmente no melhor horário. A mediação assíncrona é o mais conhecido e utilizado quando se trata de $\mathrm{EaD}$, pois possibilita ao aluno a liberdade de acessar seu conteúdo a qualquer momento.

Além de flexibilizar o acesso para o aluno, o Google Classroom permite ao professor agendar o horário em que a publicação será postada na plataforma, dessa forma, o professor pode se programar para ceder tempo e maior atenção nos fóruns criados para a turma virtual.

\footnotetext{
14 Aprendizagem assíncrona é aquela cuja interação entre participantes (professores, tutores e alunos) não necessariamente ocorre ao mesmo tempo.
} 
De acordo com Dotta et al (2013), para ter um ensino completo, o ideal é mesclar a mediação da aprendizagem combinando ferramentas síncronas ${ }^{15}$ e assíncronas, a fim de que os professores possam oferecer aos seus alunos uma inovadora experiência no ensino remoto. Diante disso, abordou-se o Google Classroom como sugestão de ferramenta assíncrona que pode ser utilizada estrategicamente e, como proposta para mediação síncrona, apresenta-se, na seção seguinte, o aplicativo ZOOM.

\section{ZoOM}

ZOOM $^{16}$ Cloud Meetings, exibido na Figura 2, é uma das maiores empresas de teleconferência do mundo. É um aplicativo fundamental para quem precisa realizar e/ou participar de reuniões em vídeo, podendo ser realizadas em dispositivos móveis com sistemas operacionais Android ou $i \mathrm{OS}$. No ZOOM é possível convidar os participantes por e-mail, SMS e redes sociais. Possui também a possibilidade de compartilhamento de arquivos, textos e apresentações durante as chamadas.

Figura 2 - Página inicial do ZOOM

\section{Reuniões Zoom}

Videoconferência Empresarial e Web Conferência

Inserir seu e-mail de trabalho

(D) Assistir ao Video
REGISTRE-SE, É GRÁTIS

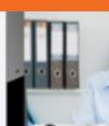

On

Ajuda

Fonte: dados da pesquisa (2020).

Com o lema "Aprendizado moderno para o aluno moderno", ZOOM (2020, online), o aplicativo abriga mais de 17.000 mil instituições educacionais, 96\% delas se tratam das principais universidades dos Estados Unidos da América (EUA), que

15 Ferramentas síncronas são online e que proporciona a interação em tempo real, instantaneamente. Webconferência, Audioconferência e Chat são algumas das ferramentas síncronas comuns na EaD.

${ }^{16}$ Site da ferramenta: https://zoom.us/pt-pt/meetings.html 
potencializam o processo de aprendizagem dos alunos usando a ferramenta para aulas virtuais e híbridas, tarefas administrativas e reuniões.

$\mathrm{Na}$ versão gratuita, a ferramenta permite realizar reuniões virtuais com até 100 participantes, com duração de 40 minutos no máximo. Na modalidade Pro ${ }^{17}$, o usuário pode fazer sessões de até 24 horas e salvar até 1 GB (Gigabyte) na nuvem por uma mensalidade de US\$14,99 (cerca de R \$ 82,25).

O ZOOM permite acessar apresentações, vídeos, documentos e outros arquivos hospedados em nuvem para apresentar aos outros usuários durante a videoconferência (ZOOM, 2020), o que favorece a apresentação do conteúdo ministrado pelo professor. O layout oportuniza que todos os participantes apareçam na tela, lado a lado, como se estivessem em sala de aula.

Com o agravamento da pandemia do COVID-19, o ZOOM anunciou que estava cedendo acesso com tempo ilimitado a seus serviços para que as escolas dos Estados Unidos, França, Dinamarca, Irlanda, Polônia e Coreia do Sul pudessem oferecer aulas em tempo real (não há informação se o mesmo será estendido ao Brasil).

Entre os benefícios pedagógicos do aplicativo, compreende-se que ele permite:

a) $\mathrm{O}$ enriquecimento do processo de ensino e o aprendizado para além dos espaços escolares, promovendo competências, estimulando a construção do conhecimento e desenvolvendo um novo paradigma, a aprendizagem ubíqua $^{18}$.

b) Potencializa a entrada de tecnologias emergentes no processo formativo do aluno que passam bastante tempo online com seus notebooks, tablets e smartphones, fomentando novos modelos de ensino e diferentes estilos de aprendizagem, transformando o modelo de ensino tradicional que, muitas vezes, não atende mais às demandas da geração de alunos cada vez mais conectada, que quer aprender de forma mais interativa, lúdica e colaborativa.

c) Aumenta os resultados de aprendizagem dos alunos, pois proporciona maior participação nas aulas e retenção do conteúdo transmitido por meio das salas de aula virtuais e híbridas (ZOOM, 2020, ONLINE). Isso ocorre porque a interatividade entre alunos e professores ocorre de forma síncrona e viabiliza a troca de experiências, bem como, a maturidade do pensamento crítico, relações de flexibilidade na transmissão de opiniões e compreensão mútua, desenvolvendo a inteligência coletiva.

\footnotetext{
17 Versão paga do ZOOM que permite reuniões com limite de duração da reunião de até 24 horas.

18 A ubiquidade permite que as TIC se apresentem potencialmente para uma construção do conhecimento mais informal, proporcionando ambientes para uma aprendizagem mais flexível e menos centralizada no espaço físico da escola. Esse processo de aprendizagem, então, ocorre através de ambientes virtuais, e atualmente, com a emergência de dispositivos móveis, novas metodologias no processo de aprendizagem são construídas e outros modelos são reformulados, caracterizando, assim, uma mudança sociocultural que altera as relações sociais, os comportamentos e as formas de perceber e se comunicar com o outro.
} 
Assim como ocorre na sala de aula presencial, esta modalidade facilita a praticidade para tirar dúvidas. O professor pode aumentar a participação dos alunos em discussões temáticas, obtendo feedback sobre as principais dúvidas e permitindo que eles façam suas perguntas e sejam valorizados no processo de aprendizagem.

Nas aulas remotas síncronas é necessário que a participação do aluno seja ativa da mesma maneira que estaria em uma aula presencial. Mas se o aluno for tímido? Vale ressaltar que a tecnologia sozinha não consegue chegar aos seus objetivos pedagógicos, é necessário que o professor encontre também formas de interagir com os alunos mais tímidos.

Diante dessa situação, é importante que os professores também devem compreender o papel deles diante do processo educacional, não só usando tecnologias, mas permitindo que o recurso utilizado posso incluir todos os alunos, de forma a atender às necessidades educacionais específicas de cada um.

As videoconferências no ZOOM são exemplos claros de aulas remotas em ferramentas síncronas, sendo que acontecem com horário marcado via transmissão em tempo real. O aluno é convidado para participar da aula por meio de um link, que o direciona para o encontro virtual no exato momento em que é transmitido (ZOOM, 2020).

As aulas podem ser concebidas no formato de videoconferência: quando proporciona o contato audiovisual entre seus participantes; ou audioconferência: quando possibilita a comunicação e a interação seja realizada por meio de áudios. Independente do formato escolhido, também existe a possibilidade de gravar a aula para que ela seja assistida ou ouvida outras vezes - de maneira assíncrona.

\section{MEDIAÇÃO EM TEMPOS DE PANDEMIA}

Regulamentada pela Portaria $n^{\circ} 343$, de 17 de março de 2020, do Ministério da Educação e por atos de alguns Conselhos Estaduais e Municipais de Educação, as aulas presenciais foram suspensas, sendo substituídas por aulas remotas. Inicia-se esta reflexão trazendo algumas especificidades sobre o desenvolvimento da educação mediada por tecnologias em tempos de pandemia.

Em uma perspectiva de oportunizar aprendizagem de forma flexível e virtual, conforme citada por Daudt (2015), acredita-se ser possível continuar desenvolvendo do processo educacional com o apoio das tecnologias, diminuindo os impactos ou efeitos do isolamento social na formação de milhares de alunos afastados da estrutura física da sala de aula presencial. 
Dessa forma, a plataforma virtual Google Classroom e o aplicativo ZOOM, estudadas nesse artigo, surgem como proposta para hospedar aulas virtuais remotas de forma síncrona e/ou assíncrona, substituindo os encontros presenciais temporariamente e tem como objetivo tornar a aprendizagem mais significativo no período de isolamento social ${ }^{19}$.

De acordo com a análise descritiva apresentada anteriormente, o Google Classroom permite total autonomia para o professor, possibilitando a personalização do ambiente virtual, assim também, como a configuração das postagens para que fique de acordo com seu planejamento didático, como indica os estudos de Conforto e Vieira (2015).

Percebe-se que, por se tratar de uma ferramenta acessível, gratuita e de fácil usabilidade, principalmente pelas pessoas que já convivem em diversos ambientes permeados de ferramentas digitais, o Google Classroom teve fácil aceitação por parte do professor: pois facilita suas atividades diárias, como a função de programar as postagem e de hospedar todas as atividades das turmas em um só lugar, dessa forma, o professor pode corrigir/analisar as atividades de forma remota, em qualquer horário e lugar, pelos diferentes dispositivos digitais.

Por se tratar de uma geração conectada, como denominada por Dotta et al (2013), os alunos também conseguem se adaptar facilmente a ferramenta, pois em um mesmo ambiente ele consegue visualizar todas as disciplinas de sua grade curricular/ano letivo de forma agrupada e ao final de cada atividade podem receber um feedback sobre o seu desempenhos nos estudos. Outro fator que também leva o Google Classroom a estar entre os aplicativos favoritos dos alunos é que, por se tratar de uma ferramenta Google, ele não ocupa a memória dos dispositivos, pois mantém os materiais (artigos, livros, vídeos e demais) compartilhados pelo professor em nuvem.

Por outro lado, o aplicativo ZOOM proporciona a interação assíncrona, realizada em tempo real, tornando todos mais próximos, mesmo que virtualmente. Dessa forma, o professor pode interagir com a turma, tirando suas dúvidas e abrindo espaços para discussões. As videoconferências no aplicativo se assemelham às aulas presenciais, pois todos estão juntos para uma finalidade, conectados ao vivo, mesmo que em espaços diferentes. Segundo Daudt (2015), as videoconferências se tornaram popular entre os alunos que, a todo momento, procuram um pouco de calor humano durante a quarentena.

Nunca perspectiva mais crítica acerca das tecnologias apresentadas neste estudo, entende-se que a inserção estratégica dos recursos supracitados não ocorre em um processo

19 O isolamento social é o comportamento onde uma pessoa ou um grupo de pessoas, voluntaria ou involuntariamente, se afastam de interações e atividades sociais. 
linear. Não basta ter essas ferramentas para fazer com que o processo formativo ocorra, é preciso que professor detenha dos conhecimentos necessários para a prática pedagógica efetiva em um ambiente de aprendizagem equipado com tecnologia. À vista disso, Conforto e Vieira (2015) meditam que a formação tecnológica dos professores garante ao aluno um acompanhamento virtual concordante com o do presencial.

Corroborando com este mesmo pensando, Dotta et al (2013), alerta que a tecnologia permite um grande acesso às informações, porém, por si só, não promove condições de aprendizagem para aqueles que têm acesso a elas. Nessa conjuntura, afirma que os profissionais de educação possuem um papel muito importante neste cenário, no qual para trabalharem respectivas tecnologias, há de se ter o domínio da técnica e o planejamento necessário.

Mesmo diante dos inúmeros relatos positivos acerca da utilização dessas ferramentas, há discursos que falam sobre as dificuldades de se adequar à essa nova realidade. Porém, sabe-se que toda transição requer adaptação, não somente dos alunos, mas de professores e gestores educacionais. Em seus estudos, Dotta et al (2013), relata que em todo processo de mudança, a exemplo do que está ocorrendo diante da pandemia do COVID - 19, uns se adaptam melhor que outros, mas que inseridos em um ambiente de cooperação e aprendizado coletivo, eventuais limitações podem ser superadas.

Por fim, considera-se que é preciso ter consciência das condições de acesso dos estudantes às tecnologias disponíveis e, principalmente à internet, para continuidade dos seus estudos de forma remota. Todo esse processo de integração das tecnologias digitais precisa garantir a participação de todos, de forma igualitária, para não gerar exclusão educacional.

\section{CONSIDERAÇÕES FINAIS}

Ao longo deste estudo, verifica-se que a mediação das tecnologias digitais para o ensino remoto em período de isolamento social, devido ao COVID - 19, é possível. Sobretudo no que diz respeito às características e funcionalidades do Google Classroom e do aplicativo ZOOM. Ambos possibilitam a interação professor/aluno de forma síncrona e/ou assíncrona, sendo capaz de tornar o processo de aprendizagem tão eficaz quanto o ensino presencial.

Não compreende os objetivos desta pesquisa fazer com que o Google Classroom e o aplicativo ZOOM passem a substituir as demais formas de transmitir conhecimento, como o quadro, o giz ou outras tecnologias já existentes. Todavia, tais recursos são apresentados como instrumentos que também apresentam suas contribuições em tempo de 
distanciamento social, tornando a aprendizagem remota mais motivacional, colaborativa, interativa e, principalmente, significativa.

O Google Classroom e o aplicativo ZOOM foram transformados temporariamente em salas de aulas virtuais, dado que o contexto pandêmico que se vive não pode interromper o processo formativo de bilhões de pessoas interessadas em colaborar para o avanço de uma sociedade que busca saídas para as diversas crises enfrentados por todos.

Constata-se, por fim, que se vive em um momento de cuidado, no qual as relações humanas, profissionais e educacionais foram redimensionadas em função do isolamento social ocasionado pelo coronavírus. As rotinas dos estudantes foram modificadas e para muitos o tempo agora é dividido com outras atividades. Porém, precisa-se refletir sobre a necessidade de adaptação dos alunos a esse novo momento, bem como aos impactos que tais mudanças podem causar, inclusive, nas condições emocionais de cada sujeito. Por isso, fique em casa!

\section{REFERÊNCIAS}

BRASIL. Portaria $\mathbf{N}^{\circ}$ 343, de 17 de março de 2020. Dispõe sobre a substituição das aulas presenciais por aulas em meios digitais enquanto durar a situação de pandemia do Novo Coronavírus - COVID-19. D.O.U 18/03/2020. Disponível em: $<$ http://www.in.gov.br/en/web/dou/-/portaria-n-343-de-17-de-marco-de-2020248564376>. Acesso em: 03 mai. 2020.

CONFORTO, Debora; VIEIRA, M. C. Smartphone na Escola: Da Discussão Disciplinar Para a Pedagógica. Latin American Journal of Computing, v. II, p. 43-54, 2015.

DAUDT, Luciano. 6 Ferramentas do google sala de aula que vão incrementar sua aula. 2020. Disponível em: https://www.qinetwork.com.br/6-ferramentas-do-googlesalade-aula-que-vao-incrementar-sua-aula/. Acesso em: 03 mai. 2020.

DOT'TA, Silvia Cristina. et al. Abordagem dialógica para a condução de aulas síncronas em uma webconferência. In: X Congresso Brasileiro de Ensino Superior a Distância, 2013, Belém. Anais do X Congresso Brasileiro de Ensino Superior a Distância. Belém: Unirede/UFPA, 2013.

GOOGLE CLASSROOM. Google for education. [S.l.: s.n.], 2020. Disponível em: < classroom.google.com>. Acesso em: 03 mai. 2020.

GSMA. GSM Association. [S.1.: s.n.], 2020. Disponível em: <https://www.gsma.com/>. Acesso em: 03 mai. 2020.

MINISTÉRIO DA SAÚDE. Painel Coronavírus (COVID - 19). 2020. Disponível em: $<$ https://covid.saude.gov.br/>. Acesso em: 03 mai. 2020.

ORGANIZAÇÃO MUNDIAL DA SAÚDE. Folha informativa - COVID-19 (doença causada pelo novo coronavírus). 2020. Disponível em: $<$ https: $/ /$ www.paho.org $/$ bra/index.php?option $=$ com_content\&view $=$ article\&id $=6101: \mathrm{co}$ vid19\&Itemid=875>. Acesso em: 03 mai. 2020. 
UNESCO. Organização das Nações Unidas para a Educação, a Ciência e a Cultura. 2020. Disponível em: < https://nacoesunidas.org/agencia/unesco/>. Acesso em: 03 mai. 2020.

UNICEF. Fundo das Nações Unidas para a Infância. 2020. Disponível em: $<$ https://www.unicef.org/brazil/>. Acesso em: 03 mai. 2020.

ZOOM. Zoom Cloud Meetings - App. [S.l.: s.n.], 2020. Disponível em: < https://zoom.us/pt-pt/meetings.html>. Acesso em: 03 mai. 2020.

Recebido em 12 mai 2020.

Publicado em 15 mai 2020.

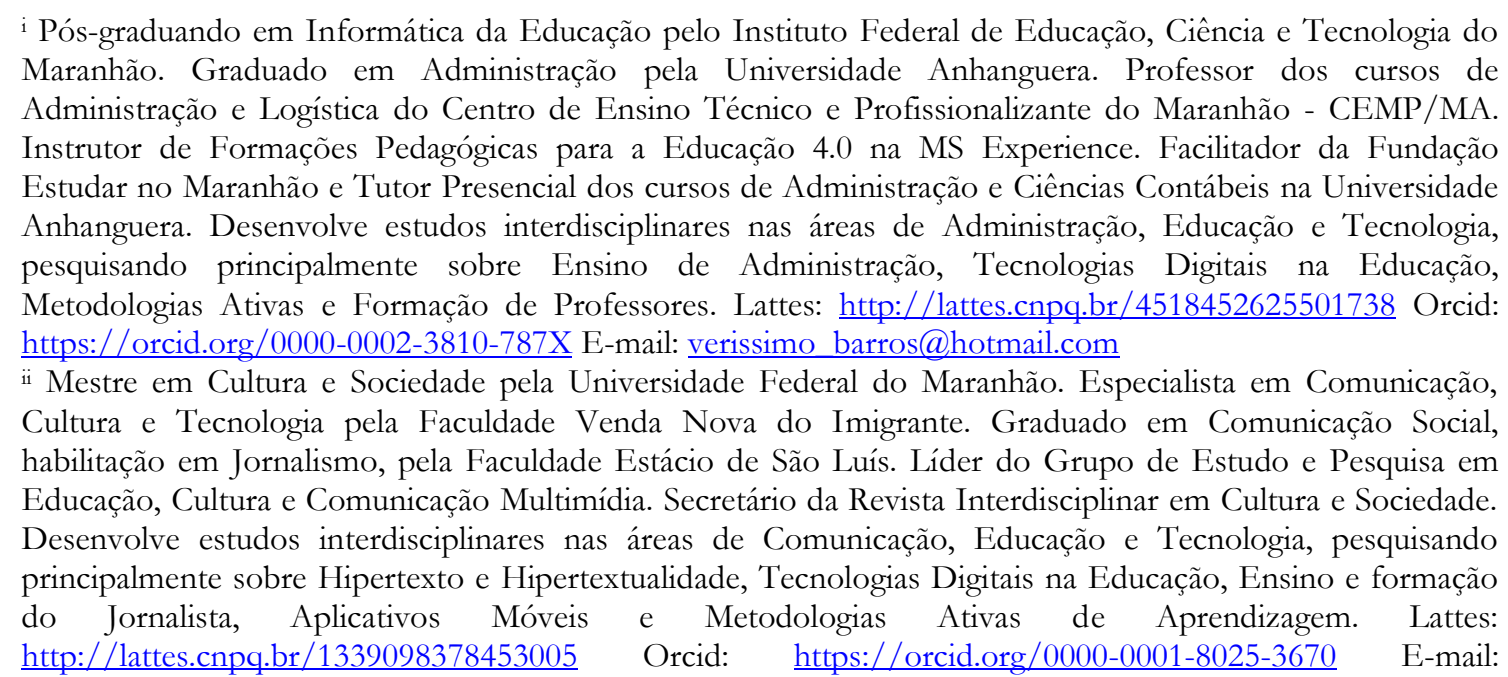
falecomjeanmonteiro@gmail.com 